\title{
Variety
Trials
}

\section{Landscape Performance of Sun Coleus in Southern Mississippi}

\author{
Christine E. Coker ${ }^{1}$, Patricia R. Knight ${ }^{2}$, and John M. Anderson ${ }^{3}$
}

AdDitional INDEX wORDs. Solenostenum scutellarioides, vigor, durability, flowering, disease resistance, pest resistance, uniqueness

Summary. Sun coleus (Solenostenum scutellarioides) are commonly used in the southern landscape. However, with the introduction of new cultivars, producers and consumers may be unaware of the selection and landscape performance of sun coleus. Sun coleus cultivars were trialed under landscape conditions at the South Mississippi Branch Station in Poplarville, Miss., in 2000 and 2001. The objective of this study was to evaluate sun coleus cultivars based on landscape performance criteria including flowering, durability, vigor, uniqueness, and insect and disease resistance. Cultivars performing well over both years included 'Ducksfoot Red,' 'Ducksfoot Tricolor', 'Ducksfoot Yellow', 'Sunflower Red', 'Pineapple', Mardi Gras', and 'Saturn'.

$\mathrm{C}$ oleus were popular in the last half of the 19th century and are once again gaining in popularity as both outdoor bedding and indoor container plants. New cultivars with increased sun and heat tolerance are being identified and are becoming increasingly available through retail garden centers as well as online and

\footnotetext{
This research supported in part by U.S. Dept. of Agriculture, Cooperative State Research, Education, and Extension Service Hatch project MIS-219020. Approved for publication as Mississippi State University Mississippi Agricultural and Forestry Experiment Station journal article J-10524. Mention of a trademark, proprietary product, or vendor does not constitute a guarantee of warranty of the product by Mississippi State University and does not imply its approval to the exclusion of other products or vendors that also may be suitable.

${ }^{1}$ Mississippi State University, Coastal Research and Extension Center, 1815 Popps Ferry Road, Biloxi, MS 39532; e-mail: ccoker@ra.msstate.edu; phone 228-388-4710.

${ }^{2}$ Mississippi State University, Coastal Research and Extension Center, 1815 Popps Ferry Road, Biloxi, MS 39532; e-mail tricia@ra.msstate.edu

${ }^{3}$ Mississippi State University, South Mississippi Branch Station, Poplarville, MS.
}

mail order sources (Armitage, 2001; Russ and Polomski, 1999; Winter 2003). One reason for the popularity of coleus is their colorful foliage which may combine shades of green, yellow, pink, red, and burgundy. Common horticultural coleus generally lumped together as Solenostemon scutellarioides include what used to be called Coleus blumei, C. xhybridus, C. pumilus, C. rehneltianus, and C. verschaffeltii. This group includes both seed-propagated and vegetatively propagated cultivars.

Coleus, described as herbs or small shrubs, are widely cultivated in window gardens and greenhouses (Armitage, 2001; Bailey, 1949). Native to the tropics and subtropics, coleus thrive in the hot, humid conditions found in the southern U.S. However, coleus are now used for accenting landscape beds in both sun and shade throughout the country.

Seed-propagated cultivars tend to do best in partial shade, produce flowers readily, and decline after flowering. Vegetatively propagated coleus are often referred to as sun coleus. These cultivars tend to exhibit more colorful foliage in direct sun, flower less, and tolerate colder temperatures than their seed-propagated counterparts (Stewart, 2003).

Within the broad categories of vegetative and seed-propagated, a cultivar may be further assigned to one of three types: landscape, novelty, or ground cover (Armitage, 2001). Landscape types are upright and less than 24 inches in height. Novelty cultivars exhibit interesting leaf characteristics such as fancy leaves or unusual coloration. Ground covers are generally more suitable for hanging baskets and containers and tend to flower more than the other types.

The objective of this study was to evaluate sun coleus cultivars based on landscape performance criteria including flowering, durability, vigor, uniqueness, and insect and disease resistance.

\section{Methods and materials}

Evaluations of 40 cultivars were conducted at the South Mississippi Branch Station in Poplarville, Miss. (USDA hardiness zone 8b) during Summer 2000. Fifty-three cultivars were evaluated in 2001. Cultivars evaluated over both years are included in Table 1. Four-inch-diameter liners were planted on 3 - $\mathrm{ft}$ centers into semi-raised beds in full sun 18-20 Apr. 2000 and 17-19 Apr. 2001 and mulched with aged pine bark to a depth of 2 inches. The soil was Ruston fine sandy loam with a $\mathrm{pH}$ of 5.8. The experimental design was a randomized complete block with three single-plant replicates. Irrigation was provided as needed through microsprinklers. Frequency and volume were determined by visual observations in order to best

\begin{tabular}{llll}
\hline $\begin{array}{l}\text { Units } \\
\begin{array}{l}\text { To convert U.S. to SI, } \\
\text { multiply by }\end{array}\end{array}$ & U.S. unit & SI unit & $\begin{array}{l}\text { To convert SI to U.S., } \\
\text { multiply by }\end{array}$ \\
\hline 0.3048 & $\mathrm{ft}$ & $\mathrm{m}$ & 3.2808 \\
2.5400 & inch $(\mathrm{es})$ & $\mathrm{cm}$ & 0.3937 \\
48.8243 & $\mathrm{lb} / \mathrm{l} 000 \mathrm{ft}^{2}$ & $\mathrm{~kg} \cdot \mathrm{ha}^{-1}$ & 0.0205
\end{tabular}


Table 1. Landscape performance of selected sun coleus cultivars based on flowering, durability, vigor, and uniqueness at the South Mississippi Branch Station at Poplarville, Miss., in 2000 and 2001. Numbers followed by different letters within a column are significantly different according to Fisher's least significant difference test (LSD) at $\alpha=0.05$.

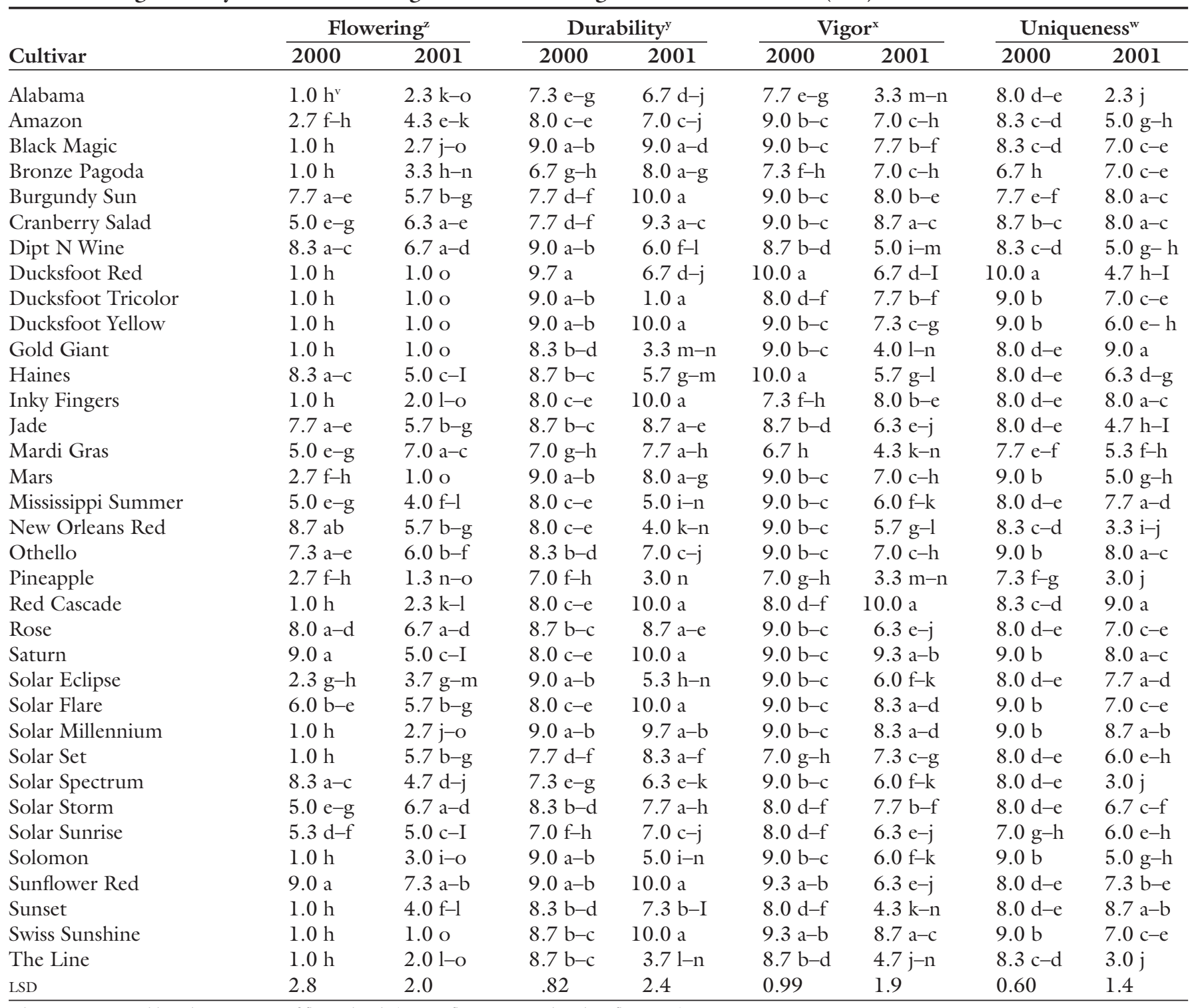

${ }^{2}$ Flowering was rated based on presence of flower heads ( 1 = no flowers; 10 = abundant flowering).

y Durability was used as a measure of tolerance to the hot, humid climatic conditions of southern Mississippi $(1=$ death; $10=$ tolerant of climate $)$.

${ }^{x}$ Vigor describes the overall health and growth performance of the plant $(1=$ slow or poor; $10=$ quick and uniform $)$.

"Uniqueness was a measure to determine the desirability of each cultivar and its difference from other cultivars within the trial $(1=$ little value; $4=$ sufficiently different and desirable; 7 = superior quality; $10=$ outstanding to superlative).

duplicate homeowner conditions. The plots were fertilized in April, June and September with agricultural grade $13-13-13(13 \mathrm{~N}-5.7 \mathrm{P}-10.8 \mathrm{~K})$ applied based on soil test recommendations at a rate of $1 \mathrm{lb} / 1000 \mathrm{ft}^{2}$ nitrogen. No insect or disease control was required throughout the test, and the flowers were not removed.

Cultivars were evaluated based on flowering, durability, vigor, uniqueness, and insect and disease resistance. All attributes were rated on a 1 to 10 scale. Flowering was rated based on presence of flower heads ( $1=$ no flowers; $10=$ abundant flowering). Durabil- ity was used as a measure of tolerance to the hot, humid climatic conditions of southern Mississippi ( $1=$ death; 10 $=$ tolerant of climate). Vigor described the overall health and growth performance of the plant $(1=$ slow or poor; $10=$ quick and uniform). Uniqueness was a measure to determine the desirability of each cultivar and its difference from other cultivars within the trial ( 1 $=$ little value; $4=$ sufficiently different and desirable; $7=$ very desirable; $10=$ outstanding to superlative). Insect and disease resistance were rated from $\mathrm{l}=$ death to $10=$ no insects or disease. One person performed all ratings over both years. One replication was evaluated at a time and plants were evaluated within replications.

Data were collected on 18 June, 18 July, and 16 Aug. in 2000 and 13 June and 10 Oct. in 2001. Data were analyzed using PROC GLM in SAS (SAS Institute, Cary, N.C.) and means were separated by the Fisher's least significant difference test (LSD) at $\propto=0.05$.

\section{Results and discussion}

2000. Coleus flowers are generally considered undesirable in the landscape, although some consumers 
find the blooms attractive. Flowering ratings ranged from 1.0-9.0 ( $\mathrm{LSD}=2.8$; Table 1). 'Saturn' and 'Sunflower Red' flowered most with an average rating of 9.0 each. This is in agreement with Owings et al. (1999) who reported profuse flowering on 'Saturn.' 'New Orleans Red' rated 8.7 and 'Dipt N Wine, 'Haines,' and 'Solar Spectrum' each rated 8.3. Similar were 'Jade' and 'Burgundy Sun' which received flowering ratings of 7.7 and 'Othello' which received a rating of 7.3 . All other cultivars rated 6.0 and below. Nearly half of the cultivars received flowering ratings of 1.0.

Durability of each cultivar was determined by its landscape performance, and ratings ranged from 6.3-9.7 (LSD $=0.82$ ). 'Ducksfoot Red' was the most durable of the cultivars observed in this study with a rating of 9.7. 'Black Magic', 'Dipt N Wine', 'Ducksfoot Tricolor', 'Ducksfoot Yellow', 'Mars', 'Solar Eclipse', 'Solar Millennium', 'Solomon', and 'Sunflower Red' were statistically similar to 'Ducksfoot Red'. Each of these cultivars received an average rating of 9.0. Winter et al. (2000) also reported 'Ducksfoot Red' and 'Ducksfoot Yellow' as well as 'Solar Eclipse' to be highly rated for landscape appeal and marketability. Least durable cultivars included 'Bronze Pagoda', 'Mardi Gras', 'Pineapple', 'Solar Furnace', and 'Solar Sunset'.

Nearly all cultivars were considered highly vigorous with ratings ranging from 6.7-10.0 ( $\mathrm{LSD}=0.99$ ). 'Ducksfoot Red' and 'Haines' were both rated 10.0. 'Sunflower Red' and 'Swiss Sunshine' were also very tolerant of the climatic conditions, both rating 9.3. 'Jade', 'Dipt N Wine', and 'The Line' were similar with each rating 8.7. Sixty percent of the 40 cultivars were rated 9.0 or greater for vigor. Least vigorous was 'Mardi Gras' with a rating of 6.7 . Only $15 \%$ of the cultivars rated below 8.0 for vigor.

'Ducksfoot Red' was rated as a superlative cultivar based on its unique leaf shape and outstanding foliage coloration. Ratings ranged from 6.7-10.0 ( $\mathrm{LSD}=0.60)$. Cultivars receiving ratings of 9.0 included 'Ducksfoot Tricolor', 'Ducksfoot Yellow', 'Mars', 'Othello', 'Saturn', 'Solar Flare', 'Solar Millennium', 'Solomon', and 'Swiss Sunshine'. There was little insect and disease pressure on the coleus in the summer of 2000. Only minor mealy bug damage was incurred along with a small amount of random feeding damage from an unidentified species. Each of the 40 cultivars rated 8.0 and above for insect and disease resistance.

2001. 'Black Dragon' and 'Midnight Skies' were the most prolific flower producers in the 2001 evaluation, rating 8.3. 'Cranberry Salad' 'Dipt N Wine', 'Kiwi Fern', 'Mardi Gras', 'Purple Emperor', 'Rose', 'Solar Storm', 'Sunflower Red', and 'Wild Lime' were all similar to 'Black Dragon' and 'Midnight Skies'. The range for flowering ratings was $1.0-8.3$ $($ LSD $=2.0)$. Nine of the 53 cultivars were rated 1.0 for lack of flowers: 'Cantigny Royal Dwarf', 'Ducksfoot Red', 'Ducksfoot Tricolor', 'Ducksfoot Yellow', 'Gold Giant', Solenostenum languinosa, 'Mars', 'Pistachio', and 'Swiss Sunshine'. Cultivars 'Alabama', 'Black Magic', 'Black Trailer', 'Golden Ruffles', 'Inky Fingers', 'Pineapple', 'Solar Millennium', 'Solomon', and 'The Line' had flowering comparable to the cultivars that rated 1.0.

Ten cultivars were given ratings of 10.0 for durability in the climatic conditions of southern Mississippi. These included 'Black Trailer', 'Burgundy Sun', 'Ducksfoot Tricolor', 'Ducksfoot Yellow', 'Inky Fingers', 'Red Cascade', 'Saturn', 'Solar Flare', 'Sunflower Red', and 'Swiss Sunshine'. Similarly durable were 'Black Magic', 'Bronze Pagoda', 'Cranberry Salad', 'Golden Ruffles', 'Jade', 'Kiwi Fern', 'Mardi Gras', 'Mars', 'Odalisque', 'Parfait', 'Rose', 'Solar Millennium', 'Solar Set', and 'Solar Storm'. Ratings all fell between 3.0 and 10.0 (LSD = 2.4). Those cultivars receiving durability ratings of less than 4 included 'Gold Giant', 'Pineapple', 'Rustic Orange', and 'The Line'. However, 'Black Dragon', 'Cranberry Splash', 'Haines', 'Midnight Skies', 'Mississippi Summer', 'New Orleans Red', 'Pistachio', 'Solar Eclipse', 'Solomon', 'Water Color', and 'Wild Lime' had similar durability ratings, although they ranked 4.0 or greater.

'Black Trailer' and 'Red Cascade' both rated $10.0(\mathrm{LSD}=1.9)$ for vigor. The plants grew quickly and uniformly. 'Cranberry Salad', 'Saturn', 'Solar Flare', 'Solar Millennium', and 'Swiss Sunshine' had similar vigor ratings compared to 'Black Trailer' and 'Red Cascade'. The least vigorous cultivars included 'Alabama', 'Black Dragon', and 'Pineapple' with ratings of 3.3 , 3.0 , and 3.3 , respectively. 'Cantigny
Royal Dwarf', 'Cranberry Splash', 'Dipt N Wine', 'Gold Giant', 'Mardi Gras', 'Midnight Skies', 'Pistachio', 'Rustic Orange', 'Sunset', 'The Line', 'Watercolor', and 'Wild Lime' had similarly poor ratings for vigor.

'Gold Giant' and 'Red Cascade' both received uniqueness ratings of 9.0. Similarly, 'Black Trailer', 'Burgundy Sun', 'Cranberry Salad', 'Haines', 'Kiwi Fern', 'Mississippi Summer', 'Othello', 'Parfait', 'Saturn', 'Solar Eclipse', 'Solar Millennium', and 'Sunset' received high uniqueness ratings. Uniqueness ratings ranged from 2.0 to $9.0(\mathrm{LSD}=1.4)$. Cultivars receiving ratings below 3.0 were 'Alabama', 'Black Dragon', 'Pineapple', 'Solar Spectrum', and 'The Line', rating 2.3, $2.0,3.0,3.0$, and 2.7 , respectively. 'New Orleans Red', which ranked 3.3, was statistically similar to cultivars with ratings of 3.0 or lower.

As in 2000, insect and disease pressure was low (data not shown). Again, only minor insect damage was observed from mealy bugs. Only 'Rustic Orange' rated below 9 for pest resistance (8.7; LSD $=0.7)$. Twelve cultivars rated between 9.0 and 9.9. All other cultivars received a rating of 10.0 .

Table 2 includes descriptive information for most of the cultivars included in these evaluations. Outstanding cultivars identified from 2 years of evaluation include 'Ducksfoot Red', 'Ducksfoot Tricolor', 'Ducksfoot Yellow', and 'Sunflower Red'. Other cultivars identified by superior performance include 'Mardi Gras', 'Pineapple', and 'Saturn'. 'Ducksfoot Red' has a mounding, uniform growth habit with consistent coloration and durable landscape performance. The interesting coloration of 'Ducksfoot Tricolor' makes this cultivar a unique addition to any landscape. It is not only unique, but is also a tough landscape performer. 'Ducksfoot Yellow' is a resilient cultivar offering excellent color contrast to the landscape. Both 'Ducksfoot Tricolor' and 'Ducksfoot Yellow' are more spreading than 'Ducksfoot Red'. 'Sunflower Red' is reminiscent of the old-fashioned coleus cultivars. It has a medium, upright growth habit and makes a bold statement in the landscape. As the name implies, 'Mardi Gras' offers a festive color combination. Splashes of bright green and purple accent this cultivar. The bright foliage of 'Pineapple' offers a tropical look in the garden. 'Saturn' was a consistent 
Table 2. Descriptions of selected coleus cultivars evaluated in 2000 and 2001 at the South Mississippi Branch Station in Poplarville, Miss.

\begin{tabular}{|c|c|}
\hline Cultivar & Description \\
\hline Alabama & Pink and gold toned leaves \\
\hline Black Magic & $\begin{array}{l}\text { Mahogany purple leaves outlined in avocado scallops; upright } \\
\text { growth habit }\end{array}$ \\
\hline Bronze Pagoda & Large, bronzy-green leaves with purple undersides \\
\hline Burgundy Sun & Large, oval to heart-shaped leaves that are rich burgundy in color \\
\hline Cranberry Salad & Gold and burgundy foliage blended in a medium-sized leaf \\
\hline Dipt N Wine & Billowy intense ochre leaves with lower third colored crimson \\
\hline Ducksfoot Red & $\begin{array}{l}\text { Small, scalloped dark red leaves; upright but compact growth } \\
\text { habit }\end{array}$ \\
\hline Ducksfoot T & Pink with yellow and green deeply lobed leaves \\
\hline Ducksfoot Yellow & Small, frilly red and gold leaves; semi-trailing growth habit \\
\hline Gold Giant & Large tawny gold leaves with burgundy undersides \\
\hline Haines & Dusky maroon fading to salmon-pink towards the leaf margins \\
\hline Inky Fingers & Small, inky dark leaves margined in gold-green \\
\hline Jade & $\begin{array}{l}\text { Jade and olive leaves with central purple splotch radiating out } \\
\text { into sunken veins with gold speckles }\end{array}$ \\
\hline Mardi Gras & Red, green, and gold leaves; compact \\
\hline Mars & Burgundy foliage resembling a fall mum; \\
\hline Mississippi Summer & Maroon, burgundy, and pink leaves with ruffled margins \\
\hline New Orleans Red & $\begin{array}{l}\text { Dark red, almost black, foliage with an iridescent bright cherry } \\
\text { center }\end{array}$ \\
\hline $\mathrm{Ot}$ & Deep purple black ruffled leaves; open pyramidal growth habit \\
\hline Pine: & Bright li \\
\hline Red Cascade & Burgundy-black leaves edged in gold; trailing growth habit \\
\hline Rose & $\begin{array}{l}\text { Deep burgundy leaves with rose coloration on veins and serrated } \\
\text { margins }\end{array}$ \\
\hline Saturn & Red leaves centered and flecked with green and gold \\
\hline Solar Eclipse & Serrated cherry red leaves w \\
\hline Solar Flare & Dimpled green foliage with purple and lime crenate margins \\
\hline Solar Millennium & Brandy leaf center with burgundy edging \\
\hline Solar Spectrum & Multi-colored green, red, and bronze leaves with serrated edges \\
\hline Solar Storm & Dark red, green, and ivory deeply cut leaves \\
\hline Sunflower Red & Burgundy-brown serrated leaves with light green edges \\
\hline Sunset & Russet red foliage; compact growth habit \\
\hline Swiss Sunshine & $\begin{array}{l}\text { Matte green scalloped leaves with black veins, golden ivory base, } \\
\text { and cerise central area }\end{array}$ \\
\hline The Line & $\begin{array}{l}\text { Medium-sized gold-green leaves with a faint burgundy line down } \\
\text { the center vein }\end{array}$ \\
\hline
\end{tabular}

performer through 2 years of trials offering large, showy purple leaves with a bright accented center.

Although considered a disadvantage in this study, there are growers who find coleus flowers favorable, and indeed, some cultivars do exhibit attractive flowers. However, although quality did not seem to be affected by flowering, it was found that plant vigor declined post-flower.

Sun coleus have been popular plants for many years and the constant introduction of new cultivars indicate that this trend will continue. The cultivars in this trial were tested in an environment consistent with homeowner conditions. The results reflect landscape performance under such conditions. This information will allow retailers to make informed recommendations to their clientele. With the advent of so many new cultivars into the market, now numbering well over 125 (Armitage, 2001), consumers are becoming more aware that they have many choices and will want to explore those possibilities in the landscape.

\section{Literature cited}

Armitage, A.M. 2001. Armitage's manual of annuals, biennials, and half-hardy perennials. Timber Press. Portland, Ore.

Bailey, L.H. 1949. Manual of cultivated plants. Macmillan, New York.

Owings, A.D., P.J. Cox, and K.M. Leader. 1999. Landscape performance of coleus cultivars. Proc. Southern Nursery Assn. Res. Conf. 44:433-435.

Russ, K. and B. Polomski. 1999. Coleus. Clemson Ext. Home and Garden Info. Ctr. 15 June 2004. <http://www.hgic/clemson.edu/factsheets/HGIC1162.htm>.

SAS Institute, Inc. 1989. SAS/STAT user's guide. Version 6 ed. SAS Inst., Cary, N.C.

Stewart, G.D. 2003. Sun coleus info page: New Leaf Nurseries. 15 June 2004 <http://www.newleafnurseries.com/clrfyfol/coleus/pages/coleusin.html>.

Winter, N., J. Curtis, and D. Tatum. 2000. Coleus cultivar performance for Mississippi landscapes. Proc. Southern Nursery Assn. Res. Conf. 45:416-417.

Winter, N. 2003. Mississippi summer sun coleus awarded. Southern Gardening. 15 July 2004. <http://www.msucares.com/ news/print/sgnews/sg02/sg020429. html>. 